\title{
Estratigrafia de seqüências em bacias sedimentares de diferentes idades e estilos tectônicos
}

\section{José Roberto Canuto ${ }^{1}$}

\begin{abstract}
Resumo O método da Estratigrafia de Seqüências, incluindo a análise seqüências de $3^{\mathrm{a}}$ ordem, foi definido, originalmente, para aplicação em bacias sedimentares de margem passiva. Tão importante mostrou-se, através de sua utilização e dos resultados obtidos, academicamente e na aplicação prática, que, fatalmente, o mesmo viria a ser tentativamente aplicado a outros tipos de bacias sedimentares, como já ocorreu, por exemplo, com sucesso, através da linha de pesquisa que vem sendo seguida, para os casos de bacias intracratônicas paleozóicas, em situação normal e em situação glaciada. Nesta oportunidade, mostra-se que o método da Estratigrafia de Seqüências pode e vem sendo aplicado, também, a bacias sedimentares instaladas em outros tipos de contextos tectônicos, bem como associadas às mais diversas idades, a partir do Arqueano. Foram considerados os seguintes casos: bacia rifte intracontinental evoluindo para margem passiva em plataforma (Grupo Caraça); bacia foreland (Grupo Bambuí); bacia extensional (Grupo Castro); bacia intracratônica (Bacia do Paraná); e bacia intracratônica glaciada (Bacia do Paraná/Subgrupo Itararé).
\end{abstract}

Palavras-chave: Estratigrafia de Seqüências, bacias sedimentares, estilos tectônicos, bacias intracratônicas glaciadas.

\begin{abstract}
Sequence stratigraphy in sedimentary basins of different ages and tectonic styles. The method of Sequence Stratigraphy, including third-order sequence analysis, was developed originally for use in passive margin sedimentary basins. The method proved its utility for both academically and practical applications, to such an extent that it inevitably was applied to other types of sedimentary basins, as, for example, in Paleozoic intracratonic basins, under normal sedimentary circumstances, as well as for glaciated situations. It is here shown that the method of Sequence Stratigraphy can and has been applied also to sedimentary basins in other types of tectonic settings of very different ages. The following cases are here considered: intracontinental rift basin evolving into a passive marginal platform (Caraça Group); foreland basin (Bambuí Group); extensional basin (Castro Group); intracratonic basin (Paraná Basin) and glaciated intracratonic basin (Paraná Basin/Itararé Subgroup).
\end{abstract}

Keywords: Sequence Stratigraphy, sedimentary basins, tectonic styles, glaciated intracratonic basins.

INTRODUÇÃO A partir da década de 1980, grandes avanços ocorreram envolvendo o estudo e a proposição de mecanismos causadores de subsidência, associados à origem e evolução de bacias sedimentares, como pode ser verificado, por exemplo, em Bally (1980).

Paralelamente aos estudos sobre subsidência, outras pesquisas tiveram amplo desenvolvimento, relacionados à sedimentação cíclica em diversas escalas, incluindo, também, diretamente associado ao interesse demonstrado por companhias de petróleo, a instalação de seqüências de $3^{\text {a }}$ ordem (Vail et al. 1977), por serem, estas, facilmente operacionais em termos do estudo estratigráfico e de predição estrutural e sedimentar, para a prospecção de hidrocarbonetos, controladas pela variação relativa do nível do mar (Posamentier et al. 1988, Van Wagoner et al. 1988).

Com relação a seqüências de $3^{\mathrm{a}}$ ordem, os autores citados no parágrafo anterior, as definiram e apresentaram idéias evolutivas para o método, criado que foi, originalmente, para aplicação em bacias sedimentares de margem passiva. Tão importante mostrou-se o método em questão, através de sua utilização e dos resultados obtidos, academicamente e na aplicação prática, que, fatalmente, o mesmo viria a ser tentativamente aplicado a outros tipos de bacias sedimentares, como ocorreu, por exemplo, com sucesso, para os casos de bacias intracratônicas paleozóicas em situação normal e em situação glaciada (Canuto 1997b, Canuto et al. 2001). Como poderá ser verificado mais adiante, o método da Estratigrafia de Seqüências pode ser aplicado, também, a bacias sedimentares instaladas em outros tipos de contextos tectônicos.

Cloetingh et al. (1985) propuseram um mecanismo tectônico para variações relativas do nível do mar, da ordem de $1-10 \mathrm{~cm} / 1000$ anos, atingindo magnitudes de até algumas centenas de metros. O modelo explica a instalação de ciclos de $3^{\mathrm{a}}$ ordem associados à variação relativa do nível do mar, suportado pela presença de esforços horizontais na litosfera devido à ocorrência de mudanças nos campos geradores dos mesmos, em escalas de tempo de poucos milhões de anos e maiores.

Cloetingh (1988), por outro lado, interpretou as variações relativas do nível do mar, incluindo as sucessões sedimentares de onlap e offlap como expressões decorrentes de processos tectônicos regionais e possivelmente globais, ao contrário de em termos de 
variações eustáticas. Entretanto, não se pode deixar de reconhecer que variações eustáticas estiveram sempre presentes e que uma separação dos dois processos não pode ser possível sem as respectivas evidências independentes que os suportem.

O modelo tectônico proposto por Cloetingh et al. (1985) representa a interação entre os esforços intraplacas e as conseqüentes deflecções da litosfera causados por sobrecarga sedimentar. Esta interação pode produzir variações relativas do nível do mar superiores a $100 \mathrm{~m}$ ao longo de poucos milhões de anos, observadas nos flancos das bacias sedimentares.

A criação de ciclos de $3^{\mathrm{a}}$ ordem associada a flutuações glaciais, incluindo grandes avanços e recuos de mantos de gelo nos continentes, segundo Cloetingh et al. (1985), não seria o único mecanismo capaz de produzi-los com uma magnitude e velocidade comparável àqueles reconhecidos no registro estratigráfico.

Considera-se que o modelo de Cloetingh et al.(1985) pode explicar flutuações contemporâneas no nível do mar em bacias sedimentares adjacentes ou próximas, mesmo que algumas sejam atingidas pela atuação glacial e outras não.

A ação de esforços horizontais variáveis não se restringe às regiões de instalação de bacias sedimentares de margens passivas, mas, também, causa modificações nos movimentos verticais em bacias intracratônicas e de foreland, ou mesmo em outros tipos de bacias, como, por exemplo, em bacias extensionais. Este mecanismo tectônico pode auxiliar na explicação de correlações observadas entre as épocas de variações do nível do mar em regiões oceânicas e intracontinentais, como notadas por Sloss (1979) e Bally (1980).

Tendo-se em conta o caso da Bacia do Paraná, no Brasil, no Subgrupo Itararé foram observadas, em campo, inúmeras falhas, provavelmente com rejeitos de componentes vertical e horizontal (em aberto para estudos), em escala regional, nas regiões sul do Estado do Paraná (por exemplo, no interior das cidades de Rio Negro e Mafra) e norte e centro-leste do Estado de Santa Catarina (por exemplo, próximo a Presidente Nereu e Rio do Sul), que atingem, também, unidades estratigráficas sobrejacentes. As falhas, de direção predominantemente NE, provavelmente correspondem a reativações de estruturas pré-cambrianas, que podem ter apresentado ciclicidade similar à reconhecida no registro sedimentar, tendo atuando ao longo de todo o Fanerozóico. Tal atividade tectônica pode ser relacionada aos mecanismos explicados em Cloetingh et al. (1985) e Cloetingh (1988).

A persistência desses movimentos tectônicos durante o tempo de evolução deposicional da arquitetura estratigráfica em discussão, ou seja, ciclos ou seqüências de $3^{\text {a }}$ ordem, favoreceu repetidamente, ao longo do tempo, a criação de espaços para acomodação de pilhas sedimentares em desenvolvimento ao longo de todo o tempo geológico, com registros aqui mostrados com idades a partir do limite superior do Arqueano, contribuindo, assim, grandemente, como forma de controle tectônico na formação de seqüências de $3^{\text {a }}$ ordem em bacias sedimentares formadas em áreas controladas por diferentes estilos tectônicos.

MATERIAIS E MÉTODOS O artigo foi desenvolvido através da utilização de resultados obtidos em áreas distintas do Brasil, interpretados pelo próprio autor, contendo informações sobre a temática "Estratigrafia de Seqüências", envolvendo situações de diferentes idades e estilos tectônicos.

A não inclusão de exemplos relativos a bacias sedimentares de margem passiva, propriamente dita, se deve ao fato de que o método da Estratigrafia de Seqüências foi originalmente criado para esse tipo de bacia sedimentar, tendo sido, já, amplamente tratados na literatura especializada disponível.

\section{RESULTADOS}

Estratigrafia de Seqüências e estilos tectônicos O trabalho clássico de Krumbein \& Sloss (1963) demonstrou, com muita propriedade, a relação direta entre tectônica e sedimentação, verificando-se que diferentes estilos tectônicos que ocorrem na crosta levam a diferentes respostas sedimentares, próprias e características para cada um desses estilos.

Entretanto, embora a variação relativa do nível do mar possa ser observada em diferentes tipos de bacias sedimentares, sejam elas, pelo menos conforme investigado até o presente, bacias intracratônicas, bacias intracratônicas glaciadas, bacias de ante-país (foreland) e bacias extencionais, formadas através da atuação de estilos tectônicos distintos, poderá colaborar na deposição de sucessões sedimentares com características próprias, controladas pelo estilo tectônico atuante. Por outro lado, no que diz respeito a segmentos específicos da curva eustática, cada um deles representativo, individualmente, de cada fase ou estágio da variação relativa do nível do mar (que caracterizam os tratos de sistemas deposicionais), acredita-se que o controle dado pelo estilo tectônico atuante não poderá evitar a criação de um arcabouço cronoestratigráfico composto por tratos de sistemas deposicionais com características próprias, cujo desenvolvimento e associação comporão seqüências de $3^{\mathrm{a}}$ ordem identificáveis em cada tipo de bacia sedimentar. A demonstração dessa afirmação é composta justamente pelos resultados que compõem o conjunto de informações divulgadas nesta oportunidade.

\section{Estratigrafia de Seqüências em bacias sedimentares de diferentes idades e estilos tectônicos}

BACIA RIFTE INTRACONTINENTAL EVOLUINDO PARA MARGEM PASSIVA EM PLATAFORMA

Arqueano Este caso é apresentado utilizando-se o exemplo da aplicação do método da Estratigrafia de Seqüências em rochas metassedimentares do Grupo Caraça, unidade basal do Supergrupo Minas (2650-2050 $\mathrm{Ma}$ ), ao longo do perfil Serra/Colégio do Caraça, na Serra do Caraça, Estado de Minas Gerais.

O Grupo Caraça constitui-se, predominantemente, de rochas metassedimentares clásticas assentadas sobre uma grande discordância regional, exposta na parte oeste do Quadrilátero Ferrífero e abaixo dos sedimentos predo- 
minantemente químicos do Grupo Itabira. Inclui as Formações Moeda, na base, e Batatal, no topo, com o início da deposição do Grupo tendo ocorrido no final do Arqueano, há cerca de 2.650 Ma (Noce 1995) ou 2.590 Ma (Renger et al. 1994), mais propriamente no limite entre o Arqueano e o Paleoproterozóico. A hipótese é reforçada pelo fato dos zircões detríticos analisados para a Formação Moeda, serem mais antigos que 2.600 Ma (Noce 1995).

Estilo tectônico De acordo com Schorscher (1992) o Supergrupo Minas se instalou durante a estruturação inicial de um sistema de rifte intracontinental evoluindo para margem continental passiva, em contexto de plataforma.

Sedimentação Segundo Renger et al. (1994) os sedimentos mais antigos da Formação Moeda são paraconglomerados depositados através de fluxos gravitacionais de sedimentos, sobrepostos por sedimentos de ambiente fluvial entrelaçado, conjunto este instalado sobre a primeira paleosuperfície do Arqueano.

Moraes (1985) reconheceu, localmente, sedimentos eólicos e Villaça (1981) descreveu duas fácies distintas na Formação Moeda: quartzitos e conglomerados fluviais, a mais comum, e quartzitos finos e filitos litorâneos localizados na porção média da unidade.

Harder \& Chamberlin (1915) utilizaram, pela primeira vez, o nome Quartzito Caraça. A unidade foi, posteriormente, elevada à categoria de grupo por Moraes Rego (1933).

Villaça (1981) descreveu fácies sedimentares nos sedimentos da Formação Moeda, segundo proposta anterior de Dorr (1969), compondo, com maior detalhe, subdivisão estratigráfica em três unidades denominadas informalmente Moeda 1, Moeda 2 e Moeda 3.

a) Unidade Moeda 1 Sedimentos basais da Formação Moeda, com até $180 \mathrm{~m}$ de espessura. É composta de metaconglomerados gradacionais, com geometria lenticular, e variações laterais freqüentes, devido a interdigitações e intercalações com quartzitos grossos a médios com estratificação cruzada acanalada, que passam a predominar ascendentemente na coluna, contendo grânulos dispersos até o contato com a unidade Moeda 2, sobrejacente. As características observadas indicam deposição em ambiente de leques aluviais e ambiente fluvial com rios entrelaçados (mar baixo).

b) Unidade Moeda 2 Recobre, em onlap, os sedimentos da unidade Moeda 1, com espessura de até $70 \mathrm{~m}$. É formada por filitos com interlaminações milimétricas de quartzito muito fino e metassiltitos com laminação horizontal, representando transgressão marinha, com estágios de mar raso, litorâneo, na parte inferior, sobrepostos a discreta sedimentação conglomerática na base, possivelmente depósitos residuais preenchendo vales incisos, passando a ambientes de águas mais profundas (mar alto). A superfície basal deste conjunto sedimentar corresponde a uma superfície transgressiva (trato transgressivo).

c) Unidade Moeda 3 Apresenta espessura de até $100 \mathrm{~m}$. É formada, na base, por metaconglomerados lenticulares, sobrepostos por quartzitos grossos, médios e finos, com estratificação cruzada acanalada, gradan- do, para cima, a quatzitos predominantemente mais finos. Segundo Villaça (1981) corresponde a estágio aluvial, passando, na fase final, a ambiente com influências de ambiente composto e alternado aluvial-marinho litorâneo, contendo estratos com laminação paralela e/ou quartzitos limpos e homogêneos, caracterizando depósitos litorâneos de praia (trato de mar baixo sobre trato transgressivo da unidade Moeda 2, passando a transgressivo, que culminou com a Formação Batatal, de offshore, correspondendo a trato de mar alto).

O contato com a unidade intermediária é brusco, passando de filitos quartzosos laminados a clásticos médios e grosseiros, representados por metaconglomerados e quartzitos.

Durante trabalhos de campo dos quais derivou parte dos dados utilizados nesta pesquisa, foi observada estratificação cruzada hummocky, na parte superior do que é considerada como unidade Moeda 3; estes metassedimentos estão localizados em altura estratigráfica interpretada por Villaça (1981) como característica de ambientes marinhos litorâneos e de praia. Os mesmos estão situados, estratigraficamente, logo abaixo dos sedimentos da Formação Batatal, típicos de ambiente de offshore, indicando contato transicional entre as duas formações, e nova transgressão (trato transgressivo no topo da unidade Moeda, para mar alto na Formação Batatal).

Conclusões $\mathrm{O}$ arcabouço cronoestratigráfico de $3^{\mathrm{a}}$ ordem para a sucessão metassedimentar do Grupo Caraça é mostrado na figura 1.

Após a recorrência de sedimentos fluviais sobre os sedimentos litorâneos da unidade Moeda 2, próximo à região de contato com a Formação Batatal, foram observados arenitos finos a médios com estratificação cruzada hummocky, prenunciando nova transgressão que, gradativamente, passa da Formação Moeda para a Formação Batatal.

A sedimentação plataformal da Formação Batatal retrata a passagem de um ambiente predominantemente continental para um ambiente marinho costeiro (Moraes 1985). Os filitos Batatal são de natureza pelítica e representam faixas onde o aporte de material terrígeno ainda era suficiente para inibir a sedimentação química ou carbonática. Esses filitos são descontínuos, o que indica a rápida redução da alimentação clástica nesta zona da bacia e transição para o ambiente onde se acumularam as formações ferríferas bandeadas da Formação Cauê.

Considera-se, então, que, para criação do cenário transicional Moeda/Batatal, houve evolução tectônica em contexto de plataforma estável com posterior rifteamento, desenvolvendo-se bacia de margem continental passiva.

A resposta sedimentar é caracterizada com conglomerados e ortoquartzitos na Formação Moeda, com sucessão vertical de sedimentos fluviais, marinhos costeiros a offshore, de transgressão marinha, sedimentos flúvio-deltaicos, progradacionais de fase tardia de mar alto, e, novamente, sedimentos fluviais e até eólicos no topo, passando a arenitos com estratificação hummocky 


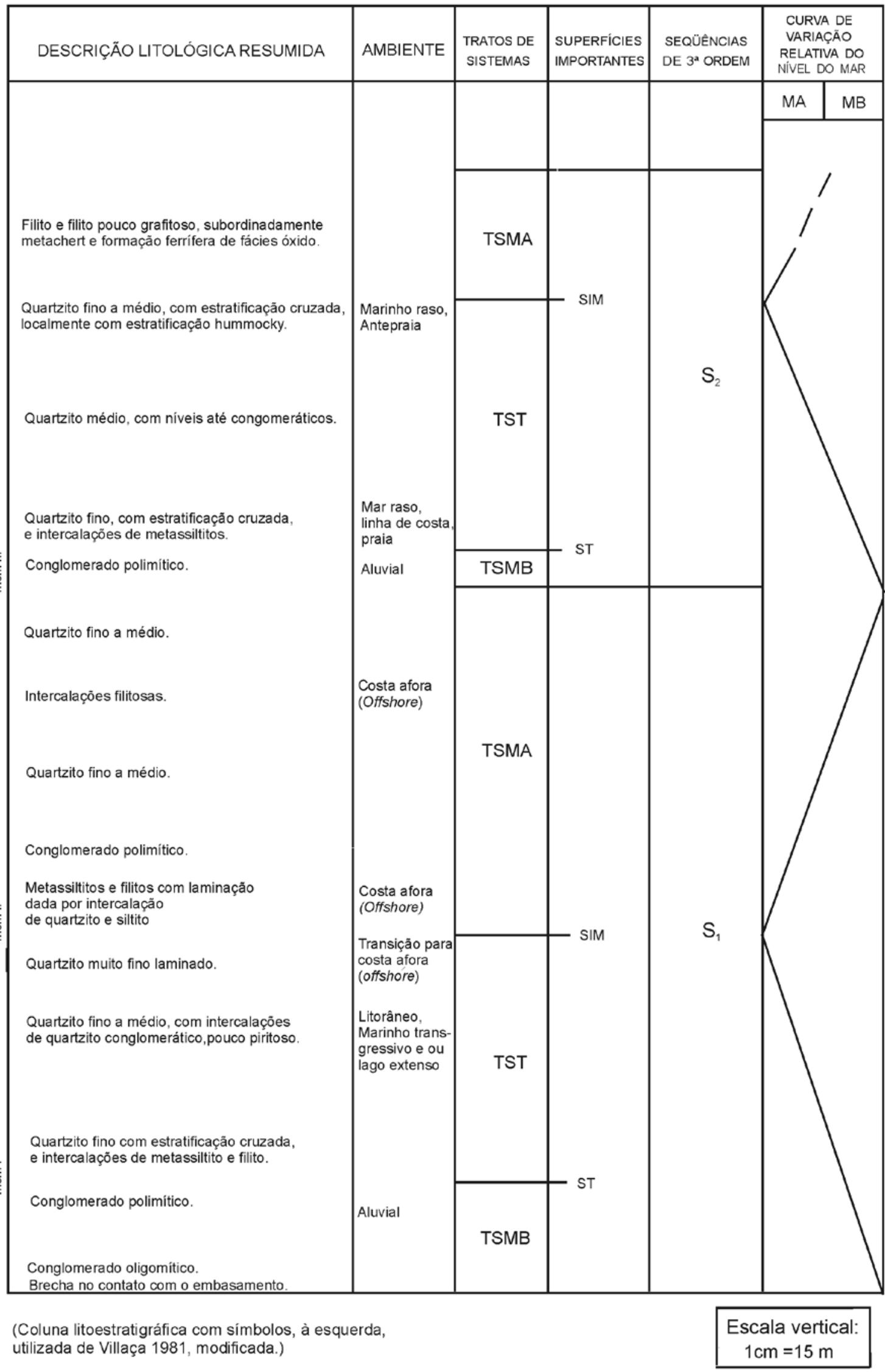

Figura 1 - Litoestratigrafia e arcabouço seqüencial de $3^{a}$ ordem do Grupo Caraça; Formação Moeda, na Serra das Gaivotas, e Formação Batatal, sobreposta. 
sobrepostos pelos sedimentos finos de offshore da Formação Batatal, mostrando nova transgressão marinha.

\section{BACIA FORELAND}

Proterozóico superior O Grupo Bambuí, utilizado como exemplo de unidade desenvolvida em bacia sedimentar proterozóica superior, se instalou entre 800 e $600 \mathrm{Ma}$ e as seções estudadas se localizam na Serra de Santa Helena e Serra da Água Fria, em Minas Gerais.

Estilo tectônico Chang et al. (1988) levantaram, inicialmente, a hipótese de evolução do Grupo Bambuí em contexto foreland, mais recentemente (Martins-Neto et al. 1997, Castro \& Dardenne 2000, Pimentel et al. 2000, Martins-Neto \& Alkmim 2001, Martins-Neto et al. 2001) considerada como deposição em bacia do tipo foreland, gerada por cavalgamentos e sobrecarga tectônica durante a orogênese brasiliana na Faixa Brasília, ao longo da margem oeste do Cráton do São Francisco, devido a colisões arco-continente e continente-continente.

Sedimentação A Serra de Santa Helena, ao norte da cidade de Sete Lagoas, apresenta rochas do Grupo Bambuí, sobre o Cráton do São Francisco, compondo as formações Sete Lagoas, Santa Helena, Lagoa do Jacaré, Serra da Saudade, e Três Marias, sobrepostas nessa ordem estratigráfica.

A Serra da Água Fria apresenta sucessão sedimentar semelhante à da Serra de Santa Helena, incluindo, porém, na base da coluna sedimentar, a unidade Jequitaí, sob a Formação Sete Lagoas. Associando-se as duas regiões serranas, tem-se a estratigrafia completa do Grupo Bambuí (Dardenne 1978, Dardenne \& Walde 1979, Dominguez 1993) na qual já se conhece sua natureza cíclica relacionada à variação relativa do nível do mar.

Tendo-se em conta como um todo, Iglesias \& Uhlein (2009) identificaram, no Grupo Bambuí, uma faciologia bastante interessante, que, em sua maior par- te, reforça o arcabouço seqüencial proposto por Canuto (1997a), aqui considerado.

Foram reconhecidos quatro ciclos sobrepostos (Canuto 1997a), da base para o topo: 1) Formação Jequitaí, com pavimentos estriados e diamictitos glaciais entre quartzitos, originados em mar raso, (Rocha-Campos et al. 1996), interdigitados com siltitos (Dominguez 1993) de mar transgressivo a alto, pela desintegração das geleiras, sugerindo, para cima, um hiato temporal, pela variação climática observada; 2) Formação Sete Lagoas, com calcários e dolomitos (mar baixo), sob a Formação Santa Helena, com folhelhos e siltitos (mar alto); 3) Formação Lagoa do Jacaré, com calcários, siltitos e margas (mar baixo), sob a Formação Serra da Saudade, com folhelhos, argilitos e siltitos (mar alto); e 4) Formação Três Marias, com arcósios (mar baixo), sob siltitos (mar alto). Os contatos entre as unidades são concordantes, bruscos ou transicionais; os clásticos marinhos sobrepõem-se aos carbonatos através de superfície de inundação marinha (Van Wagoner 1985), às vezes visíveis em afloramento.

Conclusões Comparando-se a espessura média de cada ciclo, ao redor de 100-150 m (Dardenne 1978), à de ciclos fanerozóicos (Canuto et al. 1997a), sugere-se, para o Grupo Bambuí (Canuto 1997a), quatro seqüências de $3^{\mathrm{a}}$ ordem, que têm duração média de 05-5 Ma cada uma (Vail et al. 1991), e sua inclusão, como um todo, talvez, em fase regressiva da última megasseqüência intracratônica de $2^{\mathrm{a}}$ ordem, que antecede as megasseqüências do Fanerozóico (Sloss 1963).

As seqüências de $3^{\text {a }}$ ordem do Grupo Bambuí (Fig. 2) se formaram a partir de tratos de sistemas carbonáticos de mar baixo (Haq 1991), que, além de controlados pela subsidência regional e pela variação relativa do nível do mar, atuante em sistemas siliciclásticos, são controlados, ainda, pelo clima e pela hidrografia.

A ausência de depósitos gravitacionais, comuns

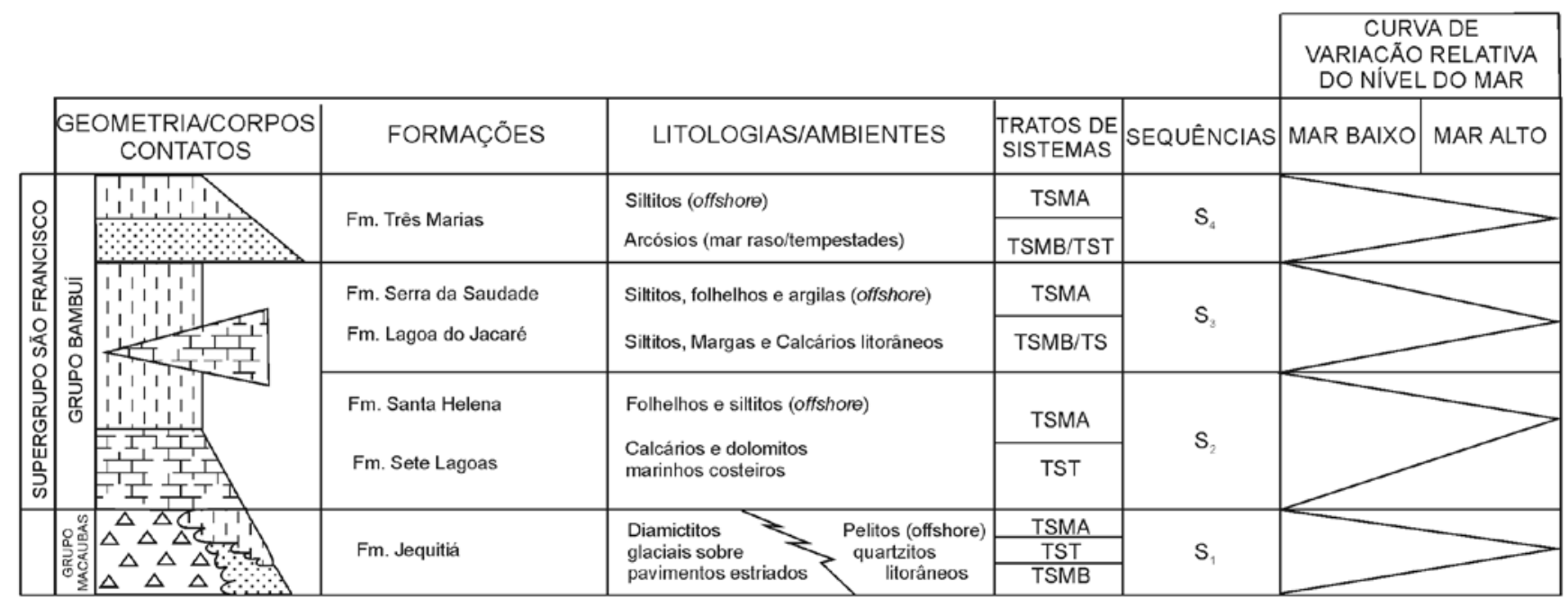

Figura 2 - Litoestratigrafia e arcabouço seqüencial de $3^{a}$ ordem do Grupo Bambuí, nas serras de Santa Helena e Água Fria, no Cráton do São Francisco. 
em taludes, sugere carbonatos formados em rampa suave, em épocas de quedas relativas mais lentas do nível do mar (velocidade de subsidência maior do que a velocidade de queda), como seqüências do tipo 2, com tratos de sistemas de margem de plataforma (Van Wagoner et al. 1988) seguidas de elevação do nível do mar.

\section{BACIAS EXTENSIONAIS}

Paleozóico inferior O Grupo Castro, utilizado como exemplo de unidade formada em bacia sedimentar de idade paleozóica inferior, foi estudado entre as cidades de Piraí do Sul e Ventania, Bacia de Castro, Estado do Paraná (Canuto 1998).

Estilo tectônico Historicamente o Grupo Castro (Ordoviciano inferior) tem sido estudado no contexto de bacia molássica pós Orogenia Brasiliana, como as bacias de Camaquã e Itajaí, no sul e sudeste do Brasil, bem como a Bacia de Jaibaras, no nordeste, desde Almeida (1969), formadas no estádio de transição, dentro do esquema de diferenciação da Plataforma Brasileira, por ele proposto. Por outro lado, as características incluindo falha de alto ângulo $\left(70^{\circ}-80^{\circ}\right)$, sedimentos mais grossos na região leste, próximo à falha e no lado mais amplo da bacia, e sedimentos mais finos em situação mais distal, para oeste, levam ao modelo de Busby \& Ingersol (1995), associado a bacia extensional, formada em regime de paraplataforma.

Sedimentação O Grupo Castro aflora numa área de cerca de $1000 \mathrm{~km}^{2}$ (Moro 1993). É recoberto erosivamente, a oeste, pelo Grupo Rio Ivaí (Ordoviciano superior-Siluriano, Assine et al. 1994), da Bacia do Paraná. Ao leste, faz contato, por falha, com o embasamento cristalino (Moro et al. 1993).

Moro (1993) identificou uma associação vulcânica intermediária a ácida, seguida de associação sedimentar inferior, nova associação vulcânica ácida, e uma associação sedimentar superior. $\mathrm{O}$ conjunto sedimentar apresenta-se dobrado mais intensamente em situação proximal, a E-SE (flancos mergulhando a $70^{\circ}-80^{\circ}$ ), e mais suavemente na região distal, a W-NW.

A associação sedimentar inferior, sobre conglomerados de leques aluviais, é formada por arcósios, siltitos, lamitos e carbonatos, preenchendo canais subaquosos, fácies de planície de inundação, e fácies lacustres, localmente com contribuições vulcânicas. Na associação sedimentar superior recorrem conglomerados de leques aluviais. Entretanto, Soares (1987) se referiu a sedimentação com influência litorânea na porção oeste da Bacia.

Canuto (1998) descreveu a sucessão estratigráfico-sedimentar para o Grupo Castro, entre as localidades de Piraí do Sul e Ventania, como segue:

a) Os primeiros conglomerados sobre as vulcânicas intermediárias a ácidas correspondem a leques aluviais mais antigos, seguidos de depósitos fluviais e de planície de inundação;

b) Rumo ao centro da Bacia, para oeste, grande parte dos depósitos considerados anteriormente (Moro 1993) como de planície de inundação, parecem corresponder, na realidade, a interlaminados de siltito e are- nitos finos depositados em planícies de marés (Canuto 1993, Canuto et al. 2001), contendo icnofósseis na forma de tubos horizontais, laminações plano-paralela horizontal, cruzada de baixo ângulo e lenticular, marcas onduladas e gretas de contração; parte dos canais subaquosos podem representar canais de maré; esse conjunto sedimentar é coberto pelos arenitos com estratificação hummocky, possivelmente de antepraia, cobertos por siltitos maciços, depositados em offshore; os carbonatos citados acima como lacustres, podem estar, alternativamente, associados a sedimentos marinhos;

c) Os conglomerados da denominada associação sedimentar superior correspondem a recorrência continental.

Conclusões Ao arcabouço estratigráfico delineado acima, aplicam-se os conceitos da Estratigrafia de Seqüências, como em outras bacias precursoras da Bacia do Paraná (Canuto 1997b). Assim, se tem (Fig. 3): a) os primeiros leques aluviais, os depósitos fluviais e os de planície de inundação equivalem a trato de sistemas deposicionais de mar baixo; b) o interlaminado de planície de maré, os canais de maré, os arenitos de antepraia, os siltitos maciços e os carbonatos compõem tratos de sistemas transgressivos e de mar alto; e c) os depósitos de leques aluviais mais jovens iniciam um novo trato de sistemas de mar baixo. Dentre esses tratos de sistemas, a) e b) formam uma seqüência de $3^{\mathrm{a}}$ ordem do tipo 2 (presença de sedimentos plataformais, e ausência de fluxos gravitacionais de sedimentos, depositados em leques de talude), e c) inicia nova seqüência de $3^{\mathrm{a}}$ ordem.

\section{BACIAS INTRACRATÔNICAS}

Paleozóico inferior a Triássico inferior sobrepostos a Vendiano e Cambriano A Bacia do Paraná está sendo utilizada como exemplo de bacia sedimentar intracratônica, considerando-se o intervalo total de duração a partir de sua instalação, no Ordoviciano superior (Milani et al. 1994), até o Triássico inferior. Os objetivos originais de Canuto (1997b) incluíram, acoplado a este pacote, o intervalo de tempo relativo à deposição de suas bacias precursoras, instaladas no âmbito da fase de transição, correspondente ao Vendiano e Cambriano, considerando-se, como exemplo, naquela ocasião, a Bacia de Castro. Foi utilizado, ainda, como fundamento, o trabalho de Canuto et al. (1997a), referente à divisão seqüencial estabelecida para o Subgrupo Itararé.

Estilo tectônico Sobre os sedimentos da Bacia de Castro (paraplataforma), desenvolveu-se a Bacia do Paraná, intracratônica, em regime de ortoplataforma.

A evolução tectono-sedimentar da Bacia do Paraná parece ter sido fortemente controlada por tendências estruturais herdadas de seu embasamento (Zalán et al. 1990). De maneira geral, uma associação de núcleos cratônicos circundados por faixas móveis pode conter um grande número de zonas de fraqueza que se interceptam, dividindo o embasamento em vários blocos limitados por falhas (Zalán et al. 1990, Milani 1992, Sanford et al. 1985). Estas zonas de fraqueza dissipa- 


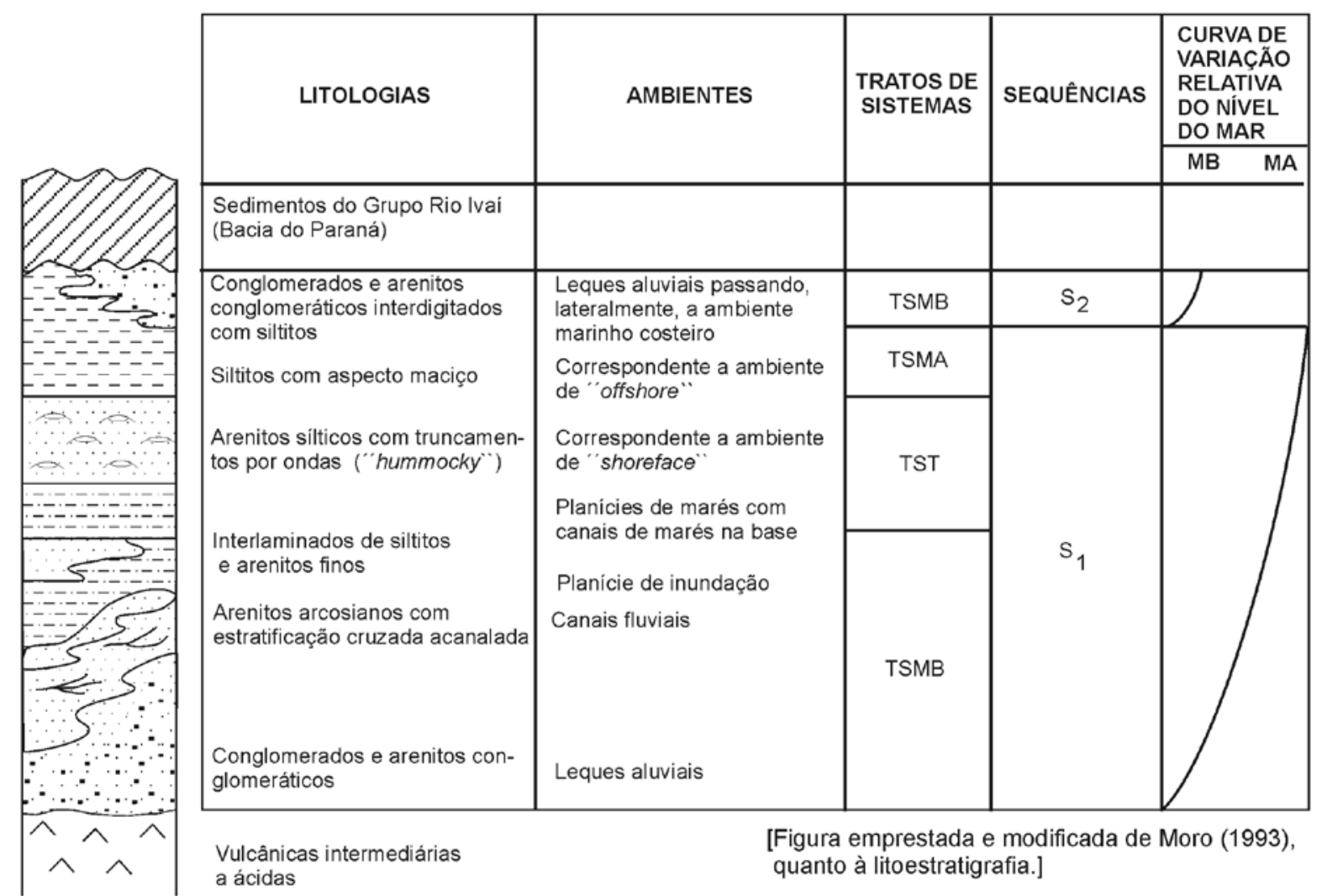

Figura 3 - Litoestratigrafia e arcabouço seqüencial de $3^{a}$ ordem do Grupo Castro, PR.

riam esforços intraplaca ao permitirem movimentos recorrentes verticais e horizontais entre blocos. Explicações semelhantes já teriam sido dadas por Cloething (1988) para a evolução de bacias intracratônicas em geral.

Os movimentos descritos acima, provavelmente de natureza sutural, foram fortes o suficiente para influenciar a distribuição de fácies sedimentares e depocentros, bem como para desenvolver deformações localizadas (Zalán et al. 1990).

Sedimentação Nas bacias intracratônicas, o cenário fisiográfico é caracterizado por margem e assoalho em forma de rampa, com mergulhos suaves, geralmente inferiores a um grau (Myers \& Milton 1998). Bacias com esse perfil são caracterizadas, da margem para as partes centrais, com linhas de tempo praticamente horizontais e uma história evolutiva composta por longos períodos de lenta acumulação de sedimentos, intercalados a períodos igualmente longos de soerguimento e erosão, resultando em sucessões sedimentares nas quais são necessários alguns ajustes para que possa ser aplicada a teoria.

Lindsay et al. (1993) aplicaram o método da Estratigrafia de Seqüências a sucessões sedimentares intracratônicas do Proterozóico superior e Paleozóico inferior da Bacia Amadeus, na Austrália central. Com relação aos problemas encontrados em cenários intracratônicos, referiram-se, eles, à forma com que se apresentam as seqüências. Afirmaram, ainda, que o trato de sistemas de mar baixo é de difícil reconhecimento e, assim, as sucessões sedimentares normalmente configuram tratos de sistemas transgressivos e de mar alto, limitados por superfícies de discordância ou paraconformidades, significando que as superfícies de máxima inundação coincidem com os limites das seqüências.

Conclusões $\mathrm{O}$ arcabouço cronoestratigráfico, aqui apresentado (Fig. 4), foi composto através de informações prévias da literatura, considerando-se seqüências já reconhecidas (Canuto 1997b, Canuto et al. 1997a).

Uma seqüência de $3^{\text {a }}$ ordem inicia-se a partir do instante de maior velocidade de queda relativa do nível do mar, evolui para uma época de mar baixo e para uma fase transgressiva, e completa-se com uma fase de mar alto, até o instante imediatamente anterior a novo momento de maior velocidade de queda relativa do nível do mar (Haq 1991).

$\mathrm{O}$ arcabouço cronoestratigráfico em discussão inicia-se a partir da primeira seqüência preservada na Bacia do Paraná, que evoluiu em condições tectônicas de ortoplataforma $\left(\mathrm{S}_{3}\right.$ ), dentro do Grupo Rio Ivaí (Assine et al. 1994), com o trato de sistemas deposicionais de mar baixo na base da Formação Alto Garças, passando, para o topo, a tratos transgressivos e de mar alto; em seguida, com o desenvolvimento de uma fase de avanço das geleiras ordoviciano-silurianas, que originou o registro sedimentar da Formação Iapó, ocorreu a deposição de novo trato de sistemas de mar baixo, sobreposto por tratos transgressivos e de mar alto, da Formação Vila Maria, caracterizando a segunda seqüência 


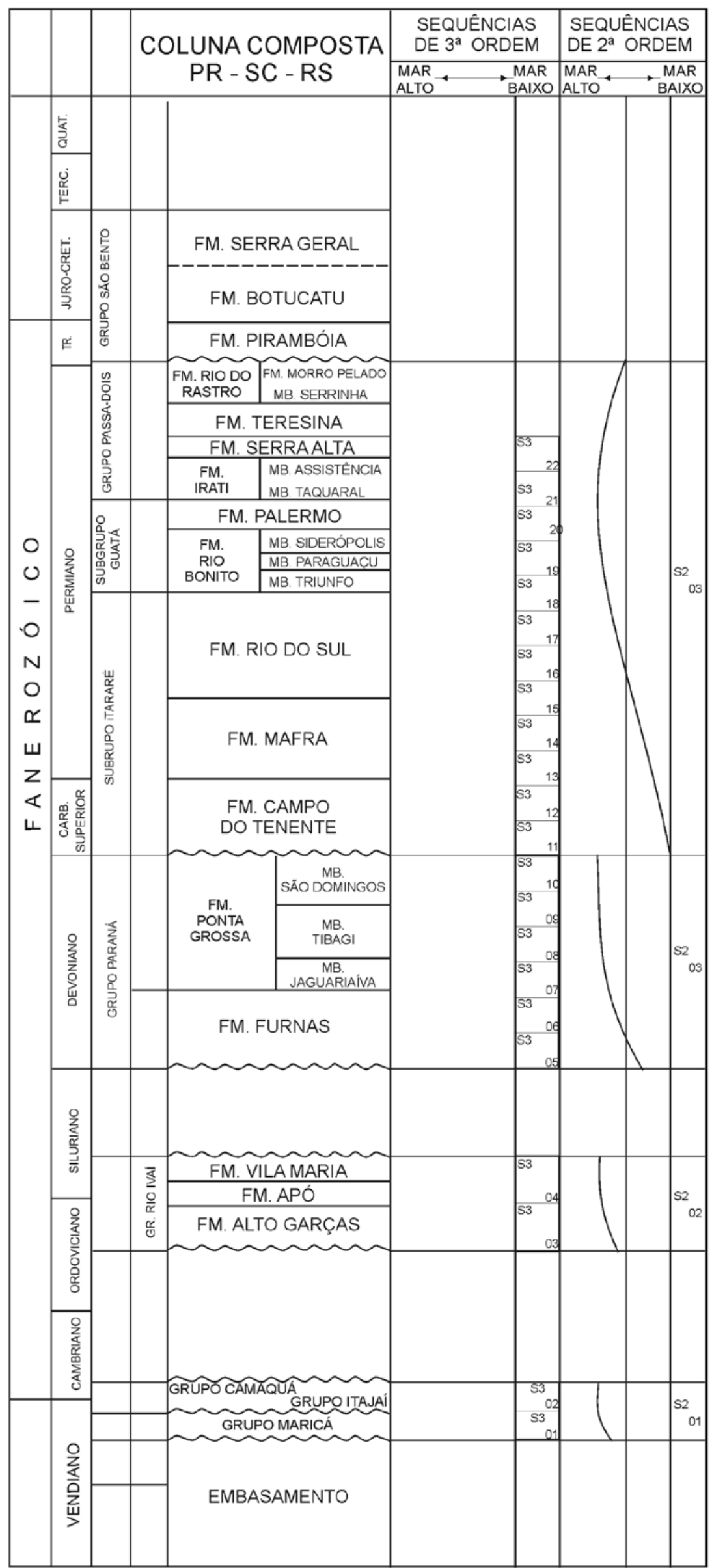

Figura 4 - Litoestratigrafia e arcabouço seqüencial de $3^{a}$ e $2^{a}$ ordens, da Bacia do Paraná. 
de $3^{\mathrm{a}}$ ordem $\left(\mathrm{S}_{4}\right)$. Seguem-se seqüências sucessivas, caracterizadas por seus elementos constituintes (tratos de sistemas), aproximadamente ao longo das seguintes unidasdes litoestratigráficas (grupos, subgrupos, formações e membros): $\mathrm{S} 3_{5}$ e $\mathrm{S} 3{ }_{6}$ incluídas na Formação Furnas; $\mathrm{S} 3$ no Membro Jaquariaíva; $\mathrm{S}_{8}$ e $\mathrm{S} 3_{9}$ no Membro Tibagi; S3 ${ }_{10}$ no Membro São Domingos; os três membros pertencem à Formação Ponta Grossa, e esta, juntamente com a Formação Furnas, compõe o Grupo Paraná.

As seqüências de $\mathrm{S} 3_{11}$ a $\mathrm{S} 3_{17}$ (parcialmente), identificadas no Subgrupo Itararé, no Paraná e em Santa Catarina (Canuto et al. 1997a, Canuto et al. 2001) foram caracterizadas incluindo-se a presença de pavimentos estriados por geleiras aterradas (Glaciação Gondvânica/Permo-Carbonífero) nas fases representativas de mar baixo, coincidentes com fases de avanço glacial. As fases de mar alto correspondem às fases de recuo do gelo. A seqüência $\mathrm{S} 3_{18}$ tem sua fase de mar baixo incluída no Membro Triunfo (Canuto 1993, Canuto et al. 2001) e sua fase de mar alto correspondendo ao Membro Paraguaçu, ambos, pertencentes à Formação Rio Bonito, do Subgrupo Guatá; a seqüência $\mathrm{S} 3{ }_{19}$ tem seu trato de sistemas de mar baixo caracterizado pelo Membro Siderópolis, também da Formação Rio Bonito, e os tratos transgressivos e de mar alto incluídos aproximadamente nos $2 / 3$ inferiores da Formação Palermo, do Subgrupo Guatá; o 1/3 superior da Formação Palermo (mar baixo) somado ao Membro Taquaral (mar alto), da Formação Irati, correspondem à seqüência $\mathrm{S}_{20}$; a seguir, considera-se o Membro Assistência (mar baixo), da Formação Irati, e a Formação Serra Alta (mar alto), nos estados do sul, concomitantemente com o Membro Assistência (mar baixo) e a Formação Corumbataí (mar alto), no Estado de São Paulo, como a seqüência $\mathrm{S}_{21}$. Neste último caso, verifica-se que a Formação Corumbataí e o Membro Assistência são separados por uma superfície de erosão (Riccomini 1995) aqui julgada como uma discordância em fase de mar baixo, porém coincidente com uma superfície de inundação marinha (Van Wagoner et al. 1988) caracterizando a base da Formação Corumbataí (tratos transgressivos e de mar alto, na seqüência $S 3_{21}$ ); para finalizar, a seqüência $S 3_{22}$ iniciou-se com a deposição da Formação Teresina, com um trato de sistemas de mar baixo, passou a mar alto pouco pronunciado no Membro Serrinha, e retornou às condições de mar baixo a partir do Membro Morro Pelado, e assim prosseguiu definitivamente devido à franca evolução da fase regressiva da seqüência de $2^{\mathrm{a}}$ ordem (Vail et al. 1977) permo-carbonífera (S2 4 ), controlada pela Orogenia Gondwanide, e correlacionável à seqüência Absaroka (Sloss 1963) limitada no topo pela discordância regional e pela concordância lateral correlativa, que separam a seqüência carbonífera superior/ permo-triássica de $2^{\mathrm{a}}$ ordem (Grupos Tubarão, transgressivo e influenciado por glaciação, e Passa-Dois, regressivo), do Grupo São Bento, com características totalmente continentais, sobrejacente.

As seqüências de $3^{\text {a }}$ ordem $\mathrm{S} 3$ e $\mathrm{S} 3{ }_{2}$ desenvolveram-se, respectivamente, nas bacias Marica e Camaquã/
Itajaí, em regime de paraplataforma, que apresentam sedimentos marinhos (Fragoso Cesar et al. 2000) e $\mathrm{S}_{2}$ na Bacia de Castro (Canuto 1998) e incluem-se como registros remanescentes da seqüência de $2^{\mathrm{a}}$ ordem vendianocambriana, cronocorrelata à seqüência Alfa (Soares et al. 1978) e à seqüência Sauk (Sloss 1963) do Cráton NorteAmericano, porém, na região sudeste do Brasil, formada em contexto tectônico de paraplataforma, associado à fase de distensão pós-Orogênese Brasiliana, também considerado (Almeida 1969) como estágio de transição para a estabilização da Plataforma Sul-Americana.

É, ainda, importante ressaltar o fato de que na maior parte da coluna sedimentar da Bacia do Paraná, as seqüências de $3^{\mathrm{a}}$ ordem mostram características similares às de seqüências do tipo 2 , por não apresentarem sedimentos depositados em ambientes de talude; entretanto, na parte relativa ao Subgrupo Itararé, as características observadas sugerem que as seqüências são do tipo 1 , considerando-se as grandes quantidades de fluxos gravitacionais de detritos presentes (Canuto 1993, Canuto et al. 2001).

\section{BACIAS INTRACRATÔNICAS GLACIADAS}

Paleozóico superior Utilizou-se, como exemplo, a Bacia do Paraná, através da análise dos sedimentos do Subgrupo Itararé, que foram depositados no Permocarbonífero, durante o desenvolvimento do evento glacial gondvânico que influenciou a Bacia como um todo (Canuto 1985, Santos 1987, Canuto et al. 2001).

Estilo tectônico Para efeito de estilo tectônico, são consideradas as mesmas características das bacias intracratônicas não glaciadas, adicionando-se o efeito glácioisostático que provoca subsidência crustal durante o avanço de mantos de gelo e soerguimento durante épocas pós-glaciais, nas quais ocorre derretimento e recuo dos mantos glaciais, causando alívio de carga sobre a crosta.

Sedimentação Diferenças importantes são observadas nas características de produtos deposicionais decorrentes de processos sedimentares atuantes em uma bacia glaciada, bem como relacionadas a conseqüências da presença de um manto glacial de alguns quilômetros de espessura sobre crosta continental.

Uma consideração importante diz respeito a que a deposição de conjuntos sedimentares envolvendo flutuações glaciais na forma de avanços e recuos de mantos de gelo em áreas continentais, atingindo, em regiões mais distais, áreas marinhas costeiras, permitiu, neste contexto sedimentar, a inclusão do registro das respectivas contribuições sedimentares derivadas dos processos deposicionais relacionados a eventos de quedas e elevações relativas do nível do mar, levando à possibilidade de identificação de ciclos de $3^{\text {a }}$ ordem, associando-se avanços e recuos glaciais respectivamente a regressões e transgressões marinhas (Canuto et al. 1997a, Canuto et al. 2001).

Contrariamente ao observado por Lindsay et al. (1993) na Bacia Amadeus, intracratônica, porém não glaciada, Canuto et al. (1997a) verificaram a presença de 
grandes espessuras de sedimentos em vários horizontes da coluna litoestratigráfica estudada, atribuíveis a tratos de sistemas de mar baixo, com predomínio da característica progradacional, sugerindo a disponibilidade de grande volume de sedimentos liberados pelo derretimento das geleiras, situação esta ausente em bacias não glaciadas.

Outro aspecto relevante, na época da deposição do Subgrupo Itararé diz respeito ao peso exercido pela presença de um manto de gelo com alguns quilômetros de espessura, sobre a margem da bacia sedimentar, como ocorre normalmente no caso da presença de geleiras de latitude próximo aos pólos (a Bacia do Paraná situava-se em latitudes ao redor de $60^{\circ}$ a $65^{\circ}$, segundo Santos et al. 1996), e à dinâmica dos avanços e recuos sucessivos das geleiras. Essas variáveis podem provocar variações tanto no volume e nos tipos de sedimentos da área continental, como variação do nível do mar e influência indireta no desenvolvimento de fácies sedimentares marinhas, formando-se, então, depósitos glácio-marinhos. Esses fatores exercem efeitos que provocam respostas diferentes, a serem consideradas quando se pretende estabelecer um arcabouço cronoestratigráfico numa bacia intracratônica glaciada.

Conclusões Canuto et al. (1997a), da análise estratigráfica de afloramentos do Subgrupo Itararé (Neopaleozóico), ao longo da seção geológica QuitandinhaCampo do Tenente-Itaiópolis, no sul do Estado do Paraná e norte do Estado de Santa Catarina, reconheceram sete ciclos sedimentares, com espessura média de 100 $\mathrm{m}$, marcando regressões e transgressões influenciadas por glaciação (Fig. 5).

A base de cada ciclo é limitada por discordância, em forma de substrato cristalino estriado, ou superfícies estriadas e/ou substrato glaciotectonizado intraformacionais, ou sua superfície correlativa. A superfície erosiva representa avanço glacial aterrado à Bacia do Paraná, através de margem de maré e, geralmente, é coberta por tilito subglacial. Folhelhos, alguns com fósseis marinhos (e.g., Ortigueira, Guaraúna e Passinho), formaram-se numa transgressão pós-glacial, e as areias finais sugerem ascensão glácio-isostática, em resposta à desintegração do lobo glacial.

As características observadas neste arcabouço estratigráfico acima levaram à aplicação dos conceitos da Estratigrafia de Seqüências. No contexto, então definido, discordâncias basais observadas nos ciclos correspondem a superfícies basais limitantes de seqüências de $3^{\mathrm{a}}$ ordem. $\mathrm{O}$ avanço do gelo sobre o assoalho da margem da bacia resulta em erosão do substrato, deposição subglacial e deslocamento de sedimentos rumo ao mar mais profundo, incluindo fluxos gravitacionais de detritos. O registro da maior parte dos depósitos de mar baixo ocorrem, então, em posição proglacial distal. Neste contexto os tilitos subglaciais correspondem a depósitos associados a fases de mar baixo, acomodados em área continental ou em área marinha de plataforma proximal. Ao recuo do gelo segue-se fase transgressiva seguida de fase de mar alto, com registro sedimentar representado, dominantemente, pela ordem, por areni- tos, siltitos, folhelhos e lamitos marinhos proglaciais, sendo seu topo uma superfície de máxima inundação (Galloway 1989), que atua como importante elemento de correlação cronoestratigráfica. Nova fase de mar baixo, associada a ajuste glácio-isostático, favorece a progradação de sedimentos marinhos rasos e de leques fluvio deltáicos, nas margens da bacia.

Considerando-se um intervalo de tempo de 15 a 36 Ma para a deposição do Subgrupo Itararé (Santos 1987), na área, a duração média de cada "ciclo" seria em torno de 2 a $5 \mathrm{Ma}$ (Canuto et al. 1997a), que equivale à das sequências de $3^{\mathrm{a}}$ ordem. A grande frequência de fluxos de massa, e as superfícies erosivas verificadas na base dos "ciclos", sugerem sequências do tipo 1 (Haq 1991, Posamentier et al. 1988, Vail et al. 1991). Os fluxos de detritos incluem-se nos sedimentos de tratos de sistemas de mar baixo, depositados em leques de talude (Van Wagoner et al. 1988). Os folhelhos Ortigueira, Guaraúna e Passinho formam tratos de sistemas transgressivo e de mar alto. O vale-túnel (Canuto et al. 1997b), preenchido pelo Arenito Lapa, formou-se subglacialmente, durante fase de mar baixo.

Em 1999, ao longo da primeira fase do projeto de pesquisa 97/13973-2, apoiado pela FAPESP e coordenado pelo autor, foram propostos, para os sedimentos do Subgrupo Itararé, no sul do Paraná e norte de Santa Catarina, os seguintes tratos de sistemas deposicionais: trato de sistemas de mar baixo (TSMB), trato de sistemas transgressivos (TST), trato de sistemas de mar alto (TSMA), e, de forma inédita, como novidade, o trato de sistemas regressivos glacioisostáticos (TSRGi), tratos de sistemas estes que foram descritos e posteriormente divulgados na literatura, por Canuto et al. (2001).

$\mathrm{O}$ arcabouço cronoestratigráfico acima delineado, como se esperava, vem sendo reconhecido, também, no Estado de São Paulo, através da análise dos sedimentos da faixa de afloramentos do Subgrupo Itararé, que vem sendo elaborada em projeto apoiado pela FAPESP, número 04/14616-4, a quem se deve também o suporte financeiro utilizado para revisão de dados na seção estudada no sul do Estado do Paraná e norte do Estado de Santa Catarina, relativos à seção geológica Quitandinha-Campo do Tenente-Itaiópolis.

De posse das situações acima demonstradas, conclui-se e confirma-se simplesmente que o método da Estratigrafia de Seqüências pode ser aplicado a situações envolvendo bacias criadas sob estilos tectônicos distintos, envolvendo, também, situação severamente influenciada por situações climáticas, como no caso de bacias glaciadas, bem como idades as mais diferentes observáveis.

Agradecimentos À Fundação de Amparo à Pesquisa do Estado de São Paulo, FAPESP, pelo apoio financeiro ao projeto $\mathrm{N}^{\circ}$ 97/13.973-2, apoio financeiro parcial, através do projeto $\mathrm{N}^{\mathrm{O}} 04 / 14.616-4$, e ao Sr. Marco Antonio Netto Chamadoira, da Seção de Ilustração Geológica, pela participação na confecção dos desenhos. 
PERFIL Q-CT-I

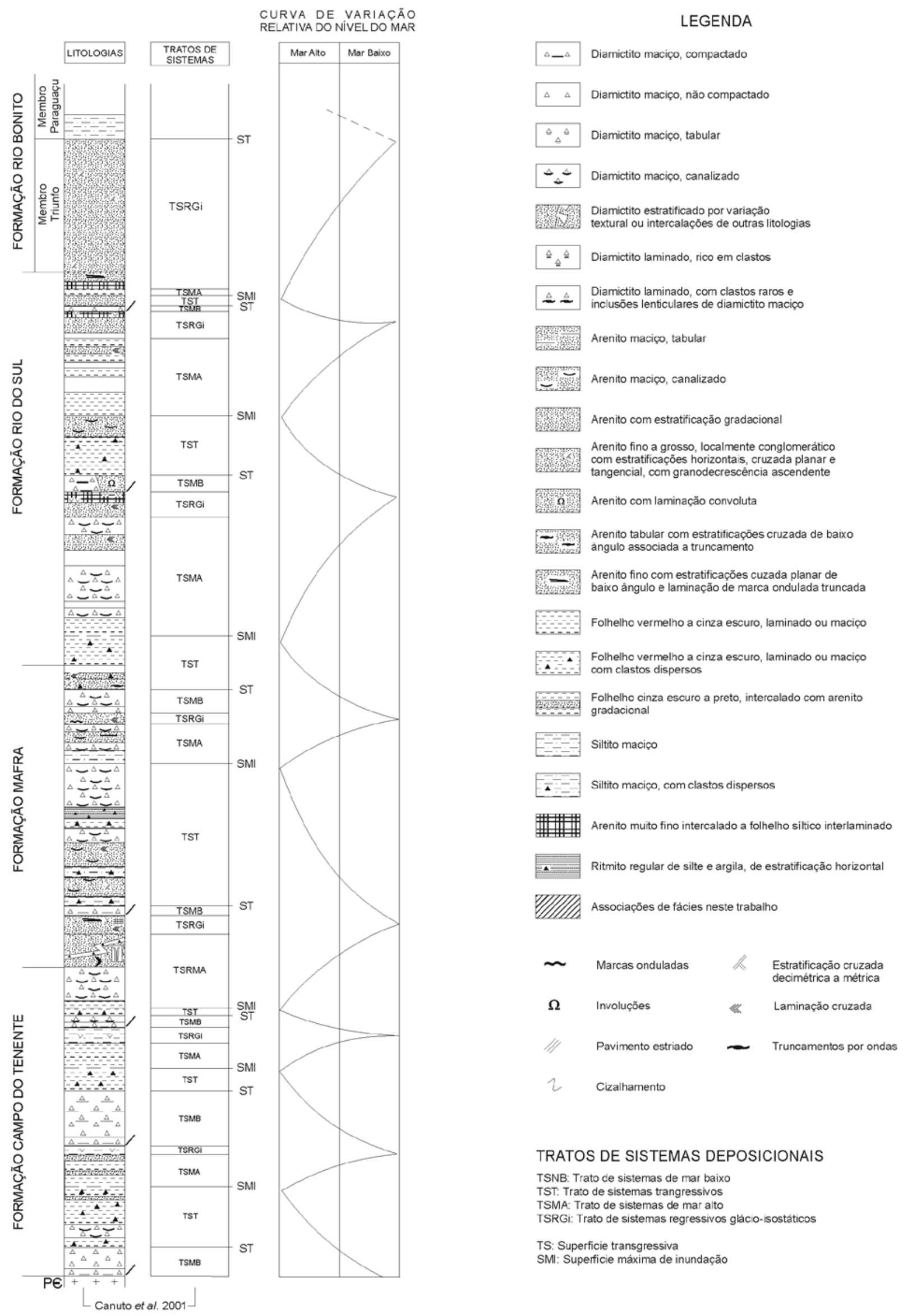

Figura 5 - Litoestratigrafia e arcabouço seqüencial de $3^{a}$ ordem da Bacia do Paraná, em sua fase glaciada (modificado de Canuto et al. 2001). 


\section{Referências}

Almeida F.F.M. 1969. Diferenciação tectônica da Plataforma Brasileira. In: SBG, Congresso Brasileiro de Geolocia, 23, Salvador, 1969. Anais, p. 29-46.

Assine M.L., Soares P.C., Milani E.J. 1994. Seqüências tectonosedimentares mesopaleozóicas da Bacia do Paraná, sul do Brasil. Revista Brasileira de Geociências, 24(2):77-89.

Bally A.W. 1980. Basins and subsidence - summary. In: Bally A.W. (ed.) Dynamics of plate interiors. American Geophysical Union Geodynamics Series, 1:1-20.

Busby C.J. \& Ingersoll R.V. 1995. Tectonic of sedimentary basins. In: Busby C.J. \& Ingersoll R.V. (eds.) Tectonic of sedimentary basins. Cap. 1, Blackwell Science, p. 1-51.

Canuto J.R. 1985. Origem dos diamictitos e de rochas associadas do Subgrupo Itararé, no sul do Estado do Paraná e norte do Estado de Santa Catarina. Dissertação de Mestrado, Inst. de Geociências, Universidade de São Paulo, São Paulo, 187 p.

Canuto J.R. 1993. Facies e ambientes de sedimentação da Formação Rio do Sul (Permiano), Bacia do Paraná, na Região de Rio do Sul, Estado de Santa Catarina. Tese de Doutoramento, IGc, Universidade de São Paulo, São Paulo, 164 p.

Canuto J.R. 1997a. Estratigrafia de sequências do Grupo Bambuí (Proterozóico superior), nas Serras de Santa Helena e da Água Fria, Minas Gerais, Brasil, com base em arcabouços cronoestratigráficos de $2^{\mathrm{a}}$ e de $3^{\mathrm{a}}$ ordens. In: SBG, Simp. de Geol.Sudeste, 5, Penedo/Itatiaia, Bol.de Resumos, p.138.

Canuto J.R. 1997b. Estratigrafia de sequências da Bacia do Paraná, Brasil, para o intervalo do Ordoviciano superior ao Triássico inferior, e de suas bacias precursoras vendiano-cambrianas, com base em arcabouços cronoestratigráficos de $2^{\mathrm{a}}$ e de $3^{\mathrm{a}}$ ordens. In: SBG, Simpósio de Geologia do Sudeste, 5, Penedo/Itatiaia, Boletim de Resumos, p. 56-57.

Canuto J.R. 1998. Estratigrafia de seqüências do Grupo Castro, na região de Piraí do Sul-Ventania, Bacia de Castro, Estado do Paraná, Brasil. Anais da Academia Brasileira de Ciências, 70(3):694-695.

Canuto J.R., Rocha-Campos A.C. \& Santos P.R. 1997a. Proposta de arcabouço cronoestratigráfico para o Subgrupo Itararé (Neopaleozóico), Bacia do Paraná. Anais da Academia Brasileira de Ciências, 69(2):277-278.

Canuto J.R., Rocha-Campos A.C., Santos P.R., Sato P.R.S. 1997b. The Late Paleozoic Lapa Sandstone (Itararé Subgroup), Paraná Basin, Brazil: a possible tunnel-valley fill? In: FG-UERJ, Simpósio sobre Cronoestratigrafia da Bacia do Paraná, 3, Barra do Garças, Abstract Volume, p. 22-23.

Canuto J.R., Santos P.R. \& Rocha-Campos A.C. 2001. Estratigrafia de seqüências do Subgrupo Itararé (Neopaleozóico) no leste da Bacia do Paraná, nas regiões sul do Paraná e norte de Santa Catarina, Brasil. Revista Brasileira de Geociências, 31(1):107-116.

Castro P.T.A. \& Dardenne M.A. 2000. The sedimentology, stratigraphy and tectonic context of the São Francisco Supergroup at the southern boundary of the São Francisco craton, Brazil. Revista Brasileira de Geociências, 30(3):345-437.

Chang H.K., Miranda F.P., Magalhães L., Alkimim F.F. 1988. Considerações sobre a evolução tectônica da bacia do São Francisco. In: SBG, Congresso Brasileiro de Geologia, 35, Belém, Anais, 5:2076-2090.

Cloetingh S. 1988. Intraplate stresses: a new element in basin analysis. In: Kleinspehn K., Paola C. (eds.) New perspectives in basin analysis. Heidelberg, New York, SpringerVerlag, p. 205-230.

Cloetingh S., McQueen H., Lambeck K. 1985. On a tectonic mechanism for regional sea-level variations. Earth Planetary Science Letters, 75:157-166.

Dardenne M.A. 1978. Síntese sobre a estratigrafia do Grupo Bambuí no Brasil Central. In: SBG, Congresso Brasileiro de Geolocia, 30, Recife, Anais, Recife, 2:597.

Dardenne M.A. \& Walde D.H.G. 1979. A estratigrafia dos Grupos Bambí e Macaúbas no Brasil Central. In: SBG-MG, Simpósio de Geologia de Minas Gerais, 1, Diamantina, Anais, 1:43-53.

Dominguez J.M.L. 1993. As coberturas do Cráton do São Francisco: uma abordagem do ponto de vista da análise de bacias. In: Domingues J.M.L. \& Misi A. (eds.) O Cráton do São Francisco. Salvador, SBG/BA-SE, SGM/BA, p. 137-159.

Dorr J.V.N. 1969. Phisiographic, stratigraphic and structural development of the Quadrilátero Ferrífero, Minas Gerais, Brazil. US Geological Survey Professional Paper 641-A:1110.

Fragoso-Cesar A.R.S., Fambrini G.L., Almeida R.P., Pelosi A.P.M.R., Janikian L., Riccomini C., Nogueira A.C.R., Saes G.S. 2000. The Camaquã Extensional Basin: Neoproterozoic-Early Paleozoic Transition in the State of Rio Grande do Sul, Brazil. Rev. Brasileira de Geociências, 30(3):438-441.

Galloway W.E. 1989. Genetic stratigraphic sequences in basin analysis, I: architecture and genesis of flooding-surface bounded depositional units. Bulletin of American Association of Petrologists and Geologists, 73:125-142.

Haq B.U. 1991. Sequence stratigraphy, sea-level change, and significance for the deep sea. In: MacDonald D.I.M. (ed.) Sedimentation, Tectonics and Eustasy - Sea-level Changes at Active Margins. Special Publication of the International Association of Sedimentologists, 12:3-39.

Harder E.C. \& Chamberlin R.T. 1915. The geology of central Minas Gerais, Brazil. Journal of Geology, 23:341-378.

Iglesias M. \& Uhlein A.2009. Estratigrafia do GrupoBambuí e coberturas fanerozóicas no vale do rio São Francisco, norte de Minas Gerais. Revista Brasileira de Geociências, 39(2):256-266.

Krumbein W.C. \& Sloss L.L. 1963. Stratigraphy and Sedimentation. $2^{\text {nd }}$ ed, San Francisco, W.H. Freeman Company, 660 p.

Lindsay J.F., Kennard J.M., Southgate P.N. 1993. Application of sequence stratigraphy in an intracratonic setting, Amadeus basin, central Australia. In: Posamentier H.W., Summerhayes C.P., Haq B.U., Allen G.P. (eds.) Sequence Stratigraphy and Facies Associations. Spec. Publ. Internat. Ass. Sedimentol., 18:605-632.

Martins-Neto M.A. \& Alkmim F.F. 2001.Estratigrafia e evolução Tectônica das bacias neoproterozóicas do paleocontinente São Francisco e suas margens: registro da quebra de Rodínia e colagem de Gondwana. In: Piva Pinto C. \& Martins-Neto M.A. (orgs.) Bacia do São Francisco, Geologia e Recursos Naturais. Belo Horizonte, Sociedade Brasileira de Geologia, Núcleo de Minas Gerais, p. 31-54.

Martins-Neto M.A., Castro P.T.A., Hercos C.M. 1997. O Supergrupo São Francisco (Neoproterozóico) no Cráton do São 
Francisco em Minas Gerais. Bol Soc. Bras. Geol., Núcleo Minas Gerais, 14:22-24.

Martins-Neto M.A., Pedrosa-Soares A.C. \& Lima S.A.A. 2001. Tectono-sedimentary evolution of sedimentary basins from Late Paleoproterozoic to Late Neoproterozoic in the São Francisco Craton and Araçuaí Fold Belt, Eastern Brazil. Sedimentary Geology, 141/142:343-370.

Milani E.J. 1992. Intraplate tectonics and evolution of the Paraná Basin, SE Brazil. In De Wit \& Ransome (Eds.), Inversion tectonics of the Cape Fold Belt, Karoo and Cretaceous basins of Southern Africa. Rotterdam, Balkema, p. 101-108.

Milani E.J., Franca A.B., Schneider R.L. 1994. Bacia do Paraná. In: Feijó F.J. (ed.) Cartas estratigráficas das bacias sedimentares brasileiras. Rio de Janeiro, Boletim Geociencias da Petrobrás, 8(2):69-82

Moraes M.A.S. 1985. Reconhecimento de facies sedimentares em rochas metamórficas da região de Outro Preto (MG). In: SBG, Simp. Geol.Minas Gerais, 3, B.Horiz, Anais, 5:84-93.

Moraes Rego L.F. 1933. As jazidas de ferro do centro de Minas Gerais. B.Horizonte, CIA Econômica Minas Gerais, 81 p.

Moro R.P.X. 1993. A bacia ordoviciana do Grupo Castro. Dissertação de Mestrado, Instituto de Geociências, Universidade Estadual Paulista, Rio Claro, 165 p.

Moro R.P.X., Bonacim E.A. \& Soares P.C. 1993.Grupo Castro: Conteúdo de uma Bacia Molássica Pós-orogênica no Cambro-Ordoviciano Paranaense. Acta Geológica Leopoldensia, XVI(37):119-134.

Myers K.J. \& Milton N.J. 1998. Concepts and Principles of Sequence Stratigraphy. In: Emery D. \& Myers K.J. (eds.) Sequence Stratigraphy. Blackwell Science, p. 11-41.

Noce C.M. 1995. Geocronologia dos eventos magmáticos e metamórficos na região do Quadrilátero Ferrífero, Minas Gerais. São Paulo, Tese de Doutoramento, Inst. De Geociências, Universidade de São Paulo, 128 p.

Pimentel M.M., Fuck R.A., Jost H., Ferreira Filho C.F., Araújo S.M. 2000. The basement of the Brasilia fold belt and the Goiás magmatic arc. In: Cordani U.G., Milani A.J., Thomaz Filho A., Campos D.A. (eds.) Tectonic Evolution of South America. International Geological Congress, 31, Rio de Janeiro, p. 195-229.

Posamentier H.W., Jervey M.T., Vail P.R. 1988. Eustatic constrols on clastic deposition, I - conceptual framework. InWilgus: C.D., Hastings B.S., Kendal C.G.St.C., Posamentier H.W., Ross C.A., Van Wagoner J.C. (eds.) Sea-level Changes: an Integrated Approach. Soc. Econ. Paleontol. Mineral., Spec. Publ., Tulsa 42:109-124.

Renger F.E., Noce C.M., Romano A.W., Machado N. 1994. Evolução sedimentar do Supergrupo Minas (500 Ma. de registro geológico), Quadrilátero Ferrífero, Minas Gerais, Brasil. Geonomos, 2:1-11.

Riccomini C. 1995. Tectonismo gerador e deformador dos depósitos sedimentares pós-gondwânicos da porção centrooriental do Estado de São Paulo e áreas vizinhas. Tese de Livre-Docência, IGc, Universidade de São Paulo, 100 p.

Rocha-Campos A.C., Young G.M., Santos P.R. 1996. Re-Examination of a striated pavement near Jequitaí, MG: Implications for Proterozoic stratigraphy and glacial geology. An. Acad. Bras. Ci., 68(4):593-594.

Sanford R.V., Thompson F.J., MacFall G.H. 1985. Plate tectonics - a possible controlling mechanism in the development of hydrocarbon traps in southwestern Ontario. Bulletin of Canadian Petroleum Geology, 33:52-71.

Santos P.R. 1987. Facies e evolução paleogeográfica do Subgrupo Itararé/Grupo Aquidanana (Neopaleozóico) na Bacia do Paraná, Brasil. São Paulo, Tese de Doutoramento, Inst. de Geociências, Universidade de São Paulo, 128 p.

Santos P.R., Rocha-Campos A.C., Canuto J.R. 1996. Patterns of late Palaeozoic deglaciation in the Paraná Basin, Brazil. Palaeogeography, Palaeoclimatology, Palaeoecology, 125:165-184.

Schorscher J.H.D 1992. Arcabouço petrográfico e evolução crustal de terrenos precambrianos do sudeste de Minas Gerais: Quadrilátero ferrífero, Espinhaço meridional e domínios granito-gnáissicos adjacentes. São Paulo, Tese de Livre-Docência, IGc, Universidade de São Paulo, 274 p.

Sloss L.L. 1963. Sequences in the cratonic interior of North America. Geological Society of America Bulletin,74:93-114.

Sloss L.L. 1979. Global sea level change; a view from the craton. In: Watkins J.S., Montadert L., Dickerson P.W. (eds.) Geological and geophysical investigation of continental margins. American Association of Petroleum Geologists Memoir, p. 461-467.

Soares P.C. 1987. Seqüências tecto-sedimentares e tectônica deformadora no centor-oeste do Escudo Paranaense. Simpósio Sul-Brasileiro de Geologia, 3, Curitiba, Atas, 2:743-771.

Soares P.C., Landim P.M.B., Fulfaro V.J. 1978. Tectonic cycles and sedimentary sequences in the Brazilian intracratonic basins. Geological Society of América Bulletin, 89:181-191.

Vail P.R., Mitchum R.M. Jr., Todd R.G., Widmier J.M., Thompson III S., Sangree J.B., Bubb J.N., Hatlelid W.G. 1977. Seismic stratigraphy and global changes of sea-level. In: Payton C.E. (ed.) Seismic stratigraphy - applications to hydrocarbon exploration. Am. Assoc. Petr. Geol., Memoir, 26:49-212.

Vail P.R., Audemard F., Bouman S.A., Eisner P.N., Perez-Cruz C. 1991. The Stratigraphic Signatures of Tectonics, Eustasy and Sedimentology - an Overview. In: Einsele G., Ricken W., Seilacher A. (eds.) Cycles and events in stratigraphy. New York, Springer-Verlag, p. 617-659.

Van Wagoner J.C. 1985. Reservoir facies distribution as controlled by sea-level change. In: Society of Economic Paleontologists and Mineralogists Mid-Year Meeting, Golden, Colorado, Abstract, August 11-14, p.91-92.

Van Wagoner J.C., Posamentier H.W., Mitchum R.M., Vail P.R., Sarg J.F., Loutit T.S., Hardenbol I. 1988. An overview of the fundamentals of sequence stratigraphy and key definitions. In: Wilgus C.K., Hastings B.S., Kendall C.G.St.C., Posamentier H.W., Ross C.A., Van Wagoner J.C. (eds.) Sea-level Changes: An Integrated Approach. Spec. Publ., Soc. Econ. Paleontol. Mineral., Tulsa, 42:39-45.

Villaça J.N. 1981. Alguns aspectos sedimentares da Formação Moeda. Sociedade. Bras. Geologia, Núcleo MG, 2:92-137.

Zalán P.V.,Wolff S., Astolfi M.A.M., Vieira I.S., Conceição J.C.J., Neto E.V.S., Marques A. 1990. The Paraná Basin, Brazil. In Leighton, Kolata, Oltz \& Eidel (eds.) Interior cratonic basins. AAPG Memoir, 51:681-708.

Manuscrito ID 16913

Submetido em 27 de fevereiro de 2010 Aceito em 30 de novembro de 2010 